\title{
Synthesis and characterization of titania nanotubes by anodizing of titanium in fluoride containing electrolytes
}

\author{
Akhlaq Ahmad ${ }^{1}$ (D) Ehsan Ul Haq ${ }^{1} \cdot$ Waseem Akhtar $^{1} \cdot$ Muhammad Arshad $^{1} \cdot$ \\ Zubair Ahmad ${ }^{2}$
}

Received: 25 July 2017/ Accepted: 22 September 2017/Published online: 6 October 2017

(c) The Author(s) 2017. This article is an open access publication

\begin{abstract}
Titania nanotubular structure was prepared by anodizing titanium metal in the fluoride containing electrolytes and studied for hydrogen reduction using photo electrochemical cell. Potentiodynamic scan was performed before actual anodizing to optimize the anodizing conditions. The morphology of the $\mathrm{TiO}_{2}$ nanotubes was investigated by SEM and the presence of $\mathrm{TiO}_{2}$ nanotubes was confirmed. Raman spectroscopy was done to confirm the different phases present. Hydrogen generation capability was revealed by electrochemical testing in three-electrode system in dark and in visible light at $200 \mathrm{~W}$ power using Gamry Potentiostat. The corrosion potential of $\mathrm{TiO}_{2}$ nanotubes produced was found to be more active side in potassium hydroxide solution under visible light than in the dark condition. Cathodic polarization behavior of specimens in the presence of light showed more activity towards hydrogen generation than in dark condition. In comparison, the hydrogen generation capability of specimen anodized in 2H15 electrolyte was higher than specimens anodized in other electrolytes. Electrochemical impedance spectroscopy was used to study the charge transfer resistance of the nanotubes produced. The results showed that $\mathrm{TiO}_{2}$ nanotubular structure is a promising material for photoelectrochemical cell. Low-charge transfer resistance also depicts that it can be efficiently used to harvest solar energy.
\end{abstract}

Akhlaq Ahmad

drakhlaq@uet.edu.pk

1 Department of Metallurgical and Materials Engineering, University of Engineering and Technology, G.T. Rd, Lahore 54890, Pakistan

2 Ibn Sina Institute of Technology, Islamabad, Pakistan
Keywords Titania nanotubes - Anodizing · Potentiodynamic scan · Harvest solar energy · Electrochemical

\section{Introduction}

Nanotubular materials are of great importance due to their exceptional physical properties and potential applications. In terms of surface activity, open mesoporous structure offers highest surface area-to-volume ratio among many other nanostructured materials (Cochran et al. 2007; Lee et al. 2011). Moreover, titania nanotubes have attracted considerable attention because of their energy applications like in photo-catalysis, photo-splitting of water, gas-sensing devices, photovoltaic devices such as dye-sensitized solar cells, and photo electrochemical cells (Lee et al. 2014). Titanium metal has an excellent corrosion resistance due to its inherent tendency to form passive oxide film. The passive oxide film formed is a semiconductor with a wide bandgap (Dobrzański et al. 2016). Techniques used for the synthesis of nanostructured titania, ranging from nanotubes to nanowires and nanopores, include hydrothermal method (Kasuga et al. 1999; Nian and Teng 2006; Tsai et al. 2006; Zhang et al. 2003), solgel technique (Momeni and Ghayeb 2016), atomic layer deposition (Knez et al. 2007; Zazpe et al. 2016; Shin et al. 2004), and anodization (Endut et al. 2013; Macak et al. 2007; Salari et al. 2011). Anodization has received attention as it is comparatively cost-effective and represents an ideal solution for developing nanostructured $\mathrm{TiO}_{2}$ for use in the variety of fields (Bozzini et al. 2008; Ellingsen 1990).

The self-organized nanotubes or nanoporous morphology of $\mathrm{TiO}_{2}$ on titanium surface can be produced in fluoride containing electrolyte by electrochemical anodization. The configuration, dimensions, shape, and activity of the 
grown nanotubes are affected by the process parameters. By varying the electrolyte composition and the potential applied, the diameter of the nanotubes in the desired narrow range can be achieved (Marichy et al. 2012). The length of the nanotubes can be increased or decreased by changing the $\mathrm{pH}$ of the electrolyte and/or by anodizing time (Sreekantan et al. 2009; Zwilling et al. 1999; Lim et al. 2012). To grow nanotubes having specific properties, the optimization of the anodizing condition is very critical. The pre-surface condition, nature of electrolyte (aqueous/organic), voltage ramp, fluoride ion concentration, and potential are all of great concern. The qualification of process parameters by potentiodynamic polarization of $\mathrm{CP}$ titanium in the desired electrolyte would be beneficial for optimization. Due to the pollution caused by and the depletion of fossil fuels, harnessing solar energy to achieve hydrogen as green energy carrier may be an alternative method to resolve the energy crisis. Since photo catalytic water splitting using $\mathrm{TiO}_{2}$ as photo anode was successfully reported by Fujishima and Honda (Fujishima and Honda 1972), $\mathrm{TiO}_{2}$ has been considered as the best hopeful material for this use owing to its extraordinary photo catalytic activity, low cost, nontoxicity, and photochemical stability (Nada et al. 2005; Kitano et al. 2007; Mishra et al. 2003; Paulose et al. 2006; Yi et al. 2008).

In the present work, $\mathrm{TiO}_{2}$ nanotubes were synthesized using different electrolytes containing varying amounts of fluoride ions by keeping voltage and anodization time constant. A very novel technique in this current research was devised in order to lower the possible amounts of $\mathrm{NH}_{4} \mathrm{~F}$ (expensive compared to diammonium phosphate) using $\left(\mathrm{NH}_{4}\right)_{2-}$ $\mathrm{HPO}_{4}$. These reduced amounts of $\mathrm{NH}_{4} \mathrm{~F}$ were proved to be beneficial in hydrogen generation and also in the application of Photo Electrochemical Cell. The morphology of synthesized nanotubes was investigated by using scanning electron microscopy. Raman spectroscopy was done to confirm the different phases of $\mathrm{TiO}_{2}$ nanotubes present. As the nanotubes were synthesized for the application in photo electrochemical cell, synthesized titania nanotubes were characterized for their electrochemical performance. Three-electrode system was employed for the testing like corrosion potential, potentiodynamic scan, and electrochemical impedance spectroscopy. A comparison of the electrochemical trends was done by testing the synthesized nanotubes in the dark and in the presence of illumination source of known intensity.

\section{Experimental}

\section{Materials}

Commercially pure titanium metal was selected as substrate material in this research work. The chemical composition of the material was determined by X-ray fluorescence (Table 1). The analytical grade chemicals, i.e., ammonium fluoride $\left(\mathrm{NH}_{4} \mathrm{~F}\right)$, diammonium phosphate $\left(\left(\mathrm{NH}_{4}\right)_{2} \mathrm{HPO}_{4}\right)$, and ethylene glycol $\left(\mathrm{C}_{2} \mathrm{H}_{6} \mathrm{O}_{2}\right)$, were used for electrochemical anodization. Ethanol and acetone were used for cleaning. All the electrolytes were prepared in deionized water. Rinsing of specimens before and after anodizing was also carried out. (Ghicov et al. 2005; Tan et al. 2012; Lim et al. 2012).

\section{Sample preparation for anodizing}

The test specimens were prepared by the following method: titanium strip of $0.8 \mathrm{~mm}$ thickness was used as substrate material. The samples were cut into sizes of $25 \mathrm{~cm} \times 12.5 \mathrm{~cm} \times 0.8 \mathrm{~mm}$. After cutting, the specimens were cold mounted and ground with emery papers of 100 , $120,180,220,320,400,600,800,1000,1200,1500,2000$, and 2500 grit size. The ground specimens were degreased in acetone and rinsed with deionized water. The samples were labelled as $2 \mathrm{H}, 2 \mathrm{H} 15$, and $2 \mathrm{H} 75$. After grinding and rinsing, one side of the specimen was insulated by the mounting material to make it nonconductive.

\section{Electrochemical anodizing}

The specimens were anodized in different electrolytes. The composition of prepared electrolytes and anodizing conditions are given in Table 2.

The anodizing of the specimens was performed in a twoelectrode cell system attached with a power supply (Matrix-MPS-3003L-3). Before connecting the sample to the anode, the power supply was turned on and required voltage was set by turning the voltage knob. Then, it was turned off after the voltage was set to the correct value. The working sample was made anode and graphite rod cathode. Properly clamped electrodes were immersed into electrolyte. Then, power supply was turned on and samples were anodized for required time. After anodizing, the samples were rinsed with deionized water and washed with ethanol. The specimens were then dried in the air.

The electrochemical optimization was investigated by means of potentiodynamic scans in electrolytes of different composition as given in Table 2 . The specimens of titanium sheet were cut into 1.0 in $\times 0.5$ in $\times 0.8 \mathrm{~mm}$ for electrochemical testing. The surface of the titanium was prepared before electrochemical testing. The primary objective of surface preparation was that the surface should response similar to commercially produced materials in electrochemical analysis. The working electrodes were ground with emery papers of up to 2500 grit size. The ground working electrodes were degreased in acetone, rinsed with deionized water, and then dried in air. The 
Table 1 Chemical composition of commercially pure titanium

\begin{tabular}{ll}
\hline Elements & Atomic\% \\
\hline Iron $(\mathrm{Fe})$ & 0.01 \\
Oxygen $(\mathrm{O})$ & 0.30 \\
Titanium $(\mathrm{Ti})$ & Balance \\
\hline
\end{tabular}

Table 2 Electrolytes composition and anodizing parameters for anodization of specimens

\begin{tabular}{llll}
\hline Chemicals & $2 \mathrm{H}$ & $2 \mathrm{H} 15$ & $2 \mathrm{H} 75$ \\
\hline $\mathrm{C}_{2} \mathrm{H}_{6} \mathrm{O}_{2}(\mathrm{ml})$ & 97 & 97 & 97 \\
$\mathrm{NH}_{4} \mathrm{~F}(\mathrm{gm})$ & 0.30 & 0.15 & 0.075 \\
$\mathrm{H}_{2} \mathrm{O}(\mathrm{ml})$ & 3 & 3 & 3 \\
$\left(\mathrm{NH}_{4}\right)_{2} \mathrm{HPO}_{4}(\mathrm{gm})$ & 0.01 & 0.01 & 0.01 \\
Voltage $(\mathrm{V})$ & 30 & 30 & 30 \\
Time (min) & 120 & 120 & 120 \\
\hline
\end{tabular}

electrochemical study was conducted in three-electrode cell in which Ti sample was used as working electrode, graphite rod as counter/auxiliary, and standard calomel electrodes as reference electrode. The samples were electrically connected with wire. Equivalent weight and exposed surface area were calculated. The experimental parameters adjusted for optimization before anodizing for the bare specimens for Electrolytes $2 \mathrm{H}, 2 \mathrm{H} 15$, and $2 \mathrm{H} 75$ are given in Table 3 .

\section{Characterization}

Anodized samples were observed at high magnification to reveal surface morphology at nanoscale by scanning electron microscope (Hitachi VP SEM S3400 N). The surface morphology of the anodized specimens was investigated by scanning electron microscope (SEM) (JSm-5600LV). The anodized specimens were investigated for the composition using energy dispersive X-ray spectroscopy (EDS).

Table 3 Input parameters for potentiodynamic scans

\begin{tabular}{ll}
\hline Parameters & Values \\
\hline Initial potential (vs. EOC) & $0 \mathrm{~V}$ \\
Final potential (vs. EOC) & $6 \mathrm{~V}$ \\
Scan rate & $10 \mathrm{mV} / \mathrm{sec}$ \\
Sample period & $1 \mathrm{~s}$ \\
Sample area & $2.58 \mathrm{~cm}^{2}$ \\
Equivalent weight & $11.97 \mathrm{~g}$ \\
Density & $4.5 \mathrm{~g} / \mathrm{cm}^{3}$ \\
\hline
\end{tabular}

The anodized specimens were tested in dark as well as in the presence of light for the comparison. A bulb of $200 \mathrm{~W}$ power was used for illumination purpose. Corrosion potential test, photodynamic polarization test, and electrochemical impedance spectroscopy (EIS) were performed in $0.5 \mathrm{M} \mathrm{KOH}$ solution.

To investigate the corrosion potential $\left(E_{\text {corr }}\right)$ of the anodized specimens, corrosion potential test was performed. The input parameter for the test is given in Table 4.

The anodized specimens were cathodically polarized in three-electrode cell system to measure corrosion potential $\left(E_{\text {corr }}\right)$, and corrosion current $\left(I_{\text {corr }}\right)$. Potentiodynamic polarization scan can also help us to validate the passivity of the samples in the particular environment. The initial delay for open circuit potential was $300 \mathrm{~s}$ and stability $0.1 \mathrm{mV} / \mathrm{s}$. During potentiodynamic polarization, the initial potential was $-0.5 \mathrm{~V}$ versus open circuit potential, the final potential was $2 \mathrm{~V}$ versus open circuit potential and scan rate of $10 \mathrm{mV} / \mathrm{s}$.

EIS was performed to observe the charge transfer behavior in that particular electrolyte. Tests were performed in dark as well as in the presence of light in $0.5 \mathrm{M}$ $\mathrm{KOH}$ solution to observe the performance of the synthesized $\mathrm{TiO}_{2}$ nanotubular structure. The test conditions and input values are given in Table 5 .

\section{Results and discussion}

\section{Electrochemical anodizing and optimization of anodizing conditions}

Table 1 shows the chemical composition of as-received Titanium metal. The chemical composition was determined by X-ray fluorescence. The polished samples ground up to 2500 grit size were anodized in three different electrolytes as mentioned in Table 2, i.e., $2 \mathrm{H}, 2 \mathrm{H} 15$, and $2 \mathrm{H} 75$. The observed color of the anodized specimens was light grey with golden shade. The organic-based electrolytes were used for the anodization.

The potentiodynamic trends (current versus potential) of as-received samples were obtained to study the variation in current under constantly increasing potential at the rate of $10 \mathrm{mV} / \mathrm{s}$ up to potential of $6 \mathrm{~V}$.

As evident in Fig. 1, the potentiodynamic scan for $2 \mathrm{H}$ sample shows that at low potential, there is an increase in value of current which depicts the dissolution of the oxide layer already formed on the surface of the substrate. After that the value of the current is slightly decreased which shows the formation of oxide layer. The value of current is then gradually increased to a maximum value, and after $1.5 \mathrm{~V}$, value of current remained almost constant. 
Table 4 Input parameters for corrosion potential

\begin{tabular}{ll}
\hline Parameters & Values \\
\hline Initial potential (vs. open circuit potential) & $0 \mathrm{~V}$ \\
Final potential (vs. open circuit potential) & $6 \mathrm{~V}$ \\
Scan rate & $10 \mathrm{mV} / \mathrm{sec}$ \\
Sample period & $0.51 \mathrm{~s}$ \\
Total time & $600 \mathrm{~s}$ \\
Sample area & $2.3 \mathrm{~cm}^{2}$ \\
Equivalent weight & $11.97 \mathrm{~g}$ \\
\hline
\end{tabular}

The low current value at higher potential suggested more dissolution rate of $\mathrm{TiO}_{2}$ than its growth and results in a nanotubular structure as confirmed by SEM analysis shown in Fig. 2. The presence of oxygen in the EDS analysis also confirms the formation of $\mathrm{TiO}_{2}$ layer (Diebold 2003; Mo and Ching 1995; Tang et al. 1994; Li et al. 2007; Yin et al. 2003; Kang 2003). The EDS spectrum of the anodized specimen in $2 \mathrm{H}$ is shown in Fig. 3 and elemental analysis is shown in Table 6.

In $2 \mathrm{H} 15$ electrolyte, the value of current reaches to $190 \mu \mathrm{A}$ at low voltage and decrease gradually, and after that, the value of current becomes constant up to $6 \mathrm{~V}$. Potentiodynamic curve of the sample is shown in Fig. 4.

SEM micrograph of the specimen has been shown in Fig. 5, after anodizing, and confirmed the formation of nanotubular structure. The EDS spectrum of $2 \mathrm{H} 15$ specimen is shown in Fig. 6. The weight $\%$ and atomic\% composition of the anodized specimen is given in Table 7. The presence of 35.77 weight $\%$ oxygen confirmed the oxide formation after anodizing.

Potentiodynamic scan for $2 \mathrm{H} 75$ sample is shown in Fig. 7. As evident from the figure, the current initially decreases near zero potential and then increases to $82 \mu \mathrm{A}$ which is then became constant up to $6 \mathrm{~V}$. This shows dissolution and growth of oxide layer, respectively (Kim et al. 2003; Kolen et al. 2003; Hoyer 1996).

Anodizing results in almost uniform porous structure with a little dissolution were confirmed by SEM analysis in

Table 5 Input parameters for electrochemical impedance spectroscopy

\begin{tabular}{ll}
\hline Parameters & Values \\
\hline Initial frequency & $10,000 \mathrm{~Hz}$ \\
Final frequency & $0.01 \mathrm{~Hz}$ \\
Points/decade & 10 \\
AC voltage & $10 \mathrm{mV}$ \\
DC voltage & $0 \mathrm{~V}$ \\
Sample area & $2.3 \mathrm{~cm}^{2}$ \\
Equivalent weight & $11.97 \mathrm{~g}$ \\
\hline
\end{tabular}

Fig. 8. The EDS spectrum of sample is shown in Fig. 9 which shows the presence of oxygen and confirmed the oxide formation. The EDS analysis for $2 \mathrm{H} 75$ is shown in Table 8.

\section{Raman spectra}

The anodized samples were characterized using Raman spectroscopy. Figure 10 shows Raman spectra of anodized samples. The spectra shows different phases of titania present having different intensities in different electrolytes. Some of the peaks were observed slightly shifted from the standard pattern, while some peaks were broadened as observed by the previous research workers (Gong et al. 2001; Ghicov et al. 2005; Bauer et al. 2006).

\section{Electrochemical analysis}

Potentiodynamic, corrosion potential, and electrochemical impedance spectroscopy analysis were examined to characterize the hydrogen reduction behavior of anodized samples in $0.5 \mathrm{M} \mathrm{KOH}$ solution in dark and in the presence of light. For illuminated characterization, the samples were irradiated by Philips Electric Fluorescent Bulb of $200 \mathrm{~W}$ power having 2725 Lumens intensity. The cell was placed in box to insulate it from surrounding light.

The electrochemical behavior of $2 \mathrm{H}, 2 \mathrm{H} 15$, and $2 \mathrm{H} 75$ samples was characterized by open circuit potential in $0.5 \mathrm{M} \mathrm{KOH}$ solution. The behavior of corrosion potential of $2 \mathrm{H}$ sample, in dark and in the presence of light, is shown in Fig. 11. The scans were obtained by exposing the surface area of $2.3 \mathrm{~cm}^{2}$ in $0.5 \mathrm{M} \mathrm{KOH}$ solution for $600 \mathrm{~s}$ using Gamry Potentiostat (PC14/750).

The corrosion potential of first sample is initially around $-0.298 \mathrm{~V}$ which gradually decreases to $-0.322 \mathrm{~V}$ when tested in the absence of any illumination. The potential of the sample, when tested in the presence of light, was around $-0.431 \mathrm{~V}$ which remains constant for the period of $600 \mathrm{~s}$ and reached to $-0.435 \mathrm{~V}$. The testing shows that the $2 \mathrm{H}$ sample has more negative potential in the light than dark which shows that more energetic electrons are available for reduction of $\mathrm{H}_{2}$.

As shown in Fig. 12, the corrosion potential for $2 \mathrm{H} 15$ in dark is the same as for $2 \mathrm{H}$, but in the presence of light, it is more negative than $2 \mathrm{H}$. The corrosion potential of sample is initially around $-0.325 \mathrm{~V}$ which gradually decreases to $-0.273 \mathrm{~V}$ when tested in the absence of any illumination. The potential of the sample, when tested in the presence of light, was around $-0.508 \mathrm{~V}$ which remains constant for the period of $600 \mathrm{~s}$ and reached to $-0.525 \mathrm{~V}$. This indicates rate of $\mathrm{H}_{2}$ reduction is higher.

The corrosion potential for $2 \mathrm{H} 75$ in $\mathrm{KOH}$ solution is shown in Fig. 13. The corrosion potential for $2 \mathrm{H} 75$ is 


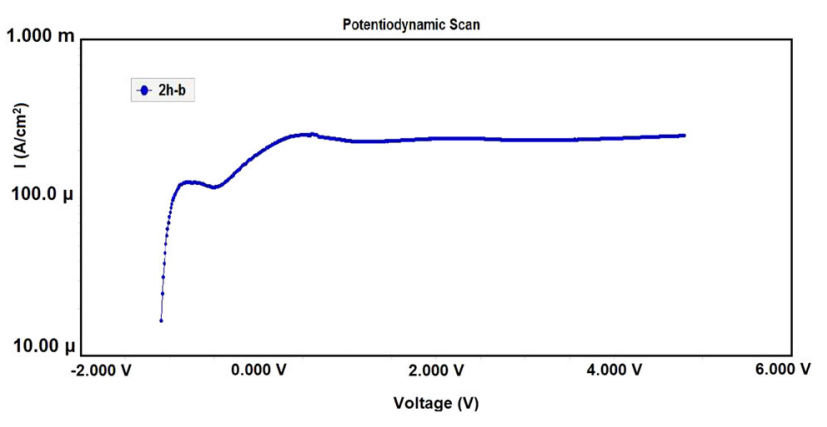

Fig. 1 Potentiodynamic scan for $2 \mathrm{H}$ sample

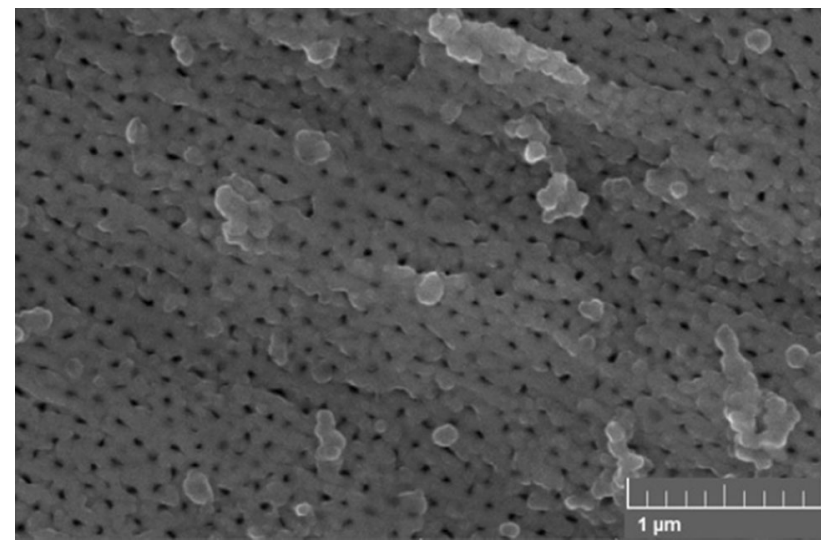

Fig. 2 SEM image of $2 \mathrm{H}$ sample

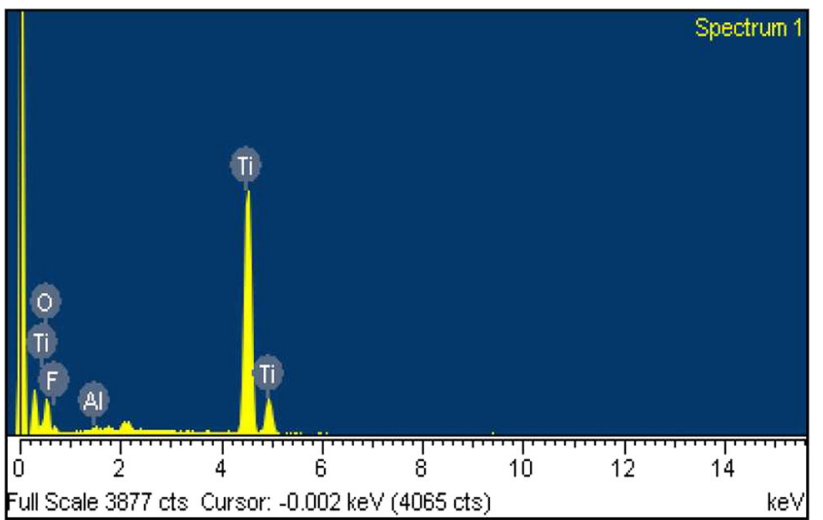

Fig. 3 EDS analysis of $2 \mathrm{H}$ sample

positive both in dark and in the presence of light as

Table 6 Elemental analysis of $2 \mathrm{H}$ sample

\begin{tabular}{lcc}
\hline Elements & Weight $\%$ & Atomic\% \\
\hline Iron (Fe) & 9.02 & 12.30 \\
Oxygen (O) & 35.44 & 57.44 \\
Aluminium (Al) & 0.45 & 0.43 \\
Titanium (Ti) & 55.09 & 29.83 \\
Total & 100.0 & 100.0 \\
\hline
\end{tabular}

compared to other two samples ( $2 \mathrm{H}$ and $2 \mathrm{H} 15)$. This shows that $\mathrm{H}_{2}$ reduction rate is lower in case of $2 \mathrm{H} 75$. The corrosion potential of the first sample was initially around $-0.129 \mathrm{~V}$ which gradually decreases to $-0.124 \mathrm{~V}$ when tested in the absence of any illumination. The potential of the sample, when tested in the presence of light, was around $-0.353 \mathrm{~V}$ which remains constant for the period of $600 \mathrm{~s}$ and reached to $-0.391 \mathrm{~V}$. The graph in Fig. 14 shows the trend of the corrosion potential of all the specimens in dark as well as in irradiated conditions and is in confirmation with the previous researchers (Ratner et al. 2008; Yao and Webster 2006; Marcus 2002).

The anodized samples were studied by potentiodynamic scans. The samples were cathodically polarized to see the capability of the specimen for hydrogen reduction. The potentiodynamic scan of specimen $2 \mathrm{H}$ is shown in Fig. 15. The specimen shows increase in the current density in the presence of light. The light promotes the reduction and, hence, the current density as a facilitating source for the voltage which imparts energy to overcome the reduction potential barrier. The value was $29.70 \mathrm{E}-06 \mathrm{~A} / \mathrm{cm}^{2}$ in the absence of light. This value increases to $71.78 \mathrm{E}-06 \mathrm{~A} / \mathrm{cm}^{2}$ which showed increase in the activity towards hydrogen reduction.

In case of the specimen $2 \mathrm{H} 15$ (the potentiodynamic scan has been shown in Fig. 16), the activity of the anodized sample was observed to be increased from $13.88 \mathrm{E}-06 \mathrm{~A} /$ $\mathrm{cm}^{2}$ in dark to $78.56 \mathrm{E}-06 \mathrm{~A} / \mathrm{cm}^{2}$ in the presence of light. This specimen shows an increase in activity to split the water in the presence of light as found by the previous researchers (Taveira et al. 2006; Sul et al. 2001; Meekins 2012; Yao and Webster 2006).

The specimen 2H75 (the potentiodynamic scan has been shown in Fig. 17) showed a different behavior than the other two samples. It shows a decrease in the current density when compared its performance in dark with that in the presence of light. The value of current was $74.02 \mathrm{E}-06 \mathrm{~A} / \mathrm{cm}^{2}$ in dark which is decreased to $9.252 \mathrm{E}-06 \mathrm{~A} / \mathrm{cm}^{2}$ when tested in the presence of light.

The Nyquist plot [Impedance (real) vs. Impedance (imaginary)] for specimen $2 \mathrm{H}$ is shown in Fig. 18. The anodized specimen showed an increase in $Z_{\text {real }}$ component in the presence of light than in the absence of light. This depicts an increase in charge transfer resistance of the anodized sample. The value of $R_{\mathrm{ct}}$ was $9.38 \mathrm{E}-05 \mathrm{~S}^{*} \mathrm{~s}^{\wedge} \mathrm{a}$ initially which slightly increase to $9.56 \mathrm{E}-05 \mathrm{~S}^{*} \mathrm{~s}^{\wedge} \mathrm{a}$.

In case of $2 \mathrm{H} 15$ specimen, the value of $R_{\mathrm{ct}}$ was $2.86 \mathrm{E}-04 \mathrm{~S}^{*} \mathrm{~s}^{\wedge} \mathrm{a}$ in dark which then decreased to a value of $1.11 \mathrm{E}-04 \mathrm{~S}^{*} \mathrm{~s}^{\wedge} \mathrm{a}$. This recession in the value of $R_{\mathrm{ct}}$ depicted a decrease in the charge transfer resistance which means more capability to reduce the hydrogen in the presence of light. The EIS scan is shown in Fig. 19. 


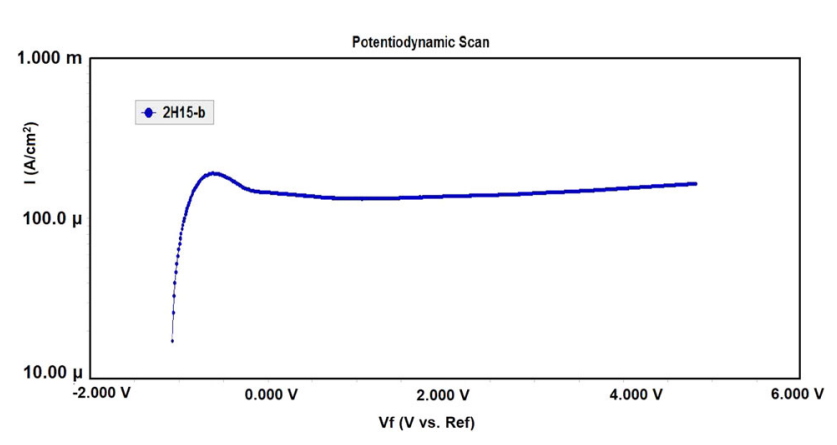

Fig. 4 Potentiodynamic scan for 2H15 sample

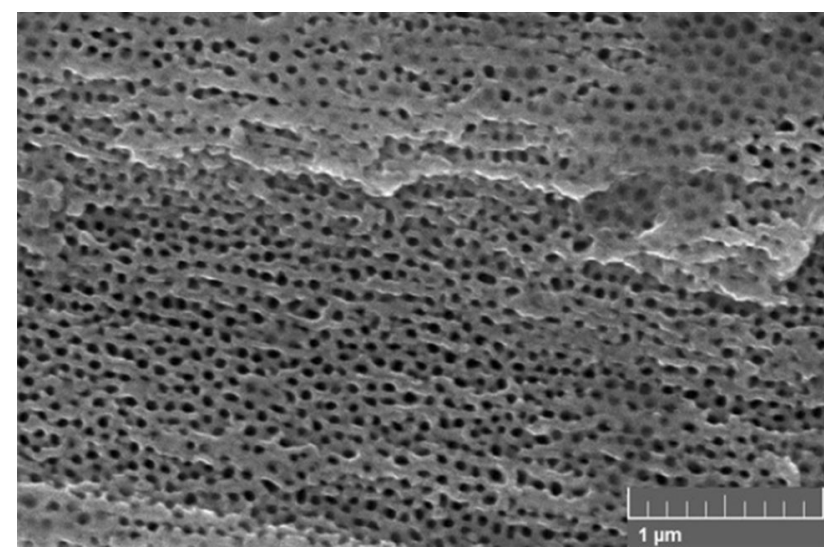

Fig. 5 SEM image of $2 \mathrm{H} 15$ sample

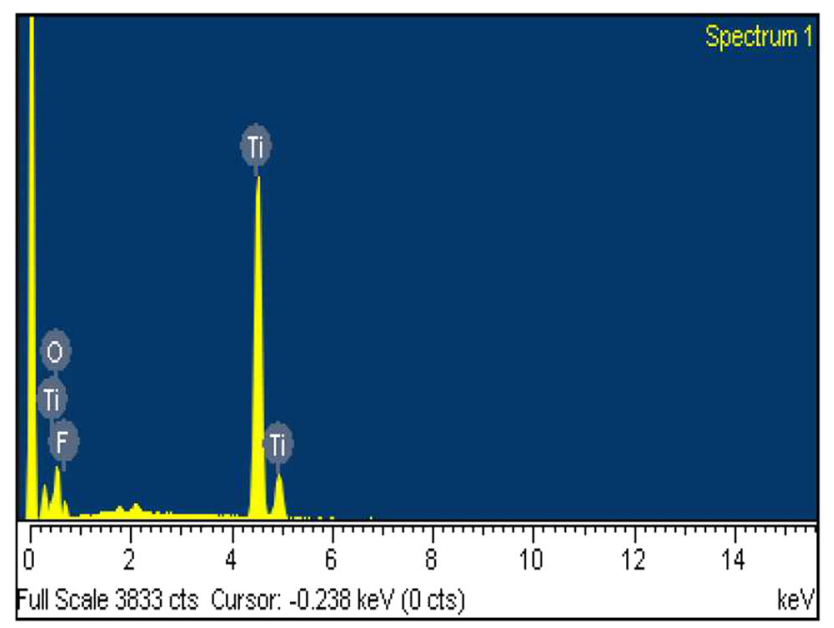

Fig. 6 EDS analysis of 2H15 sample

Table 7 Elemental analysis of 2H15 sample

\begin{tabular}{lcc}
\hline Elements & Weight $\%$ & Atomic\% \\
\hline Iron $(\mathrm{Fe})$ & 10.39 & 14.21 \\
Oxygen $(\mathrm{O})$ & 35.52 & 56.96 \\
Titanium $(\mathrm{Ti})$ & 54.09 & 28.83 \\
Total & 100.0 & 100.0 \\
\hline
\end{tabular}

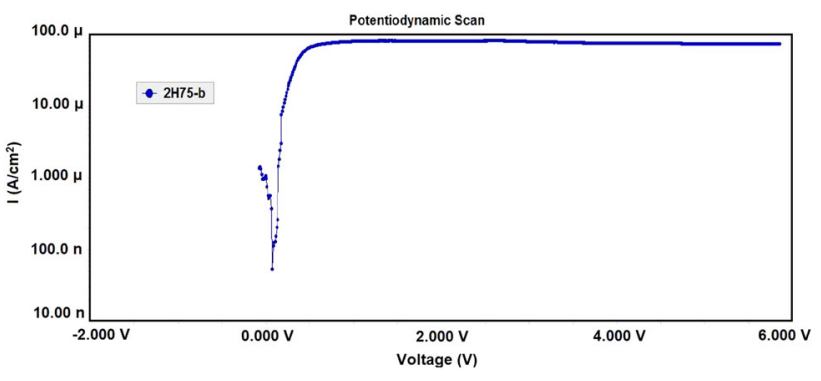

Fig. 7 Potentiodynamic scan for $2 \mathrm{H} 75$ sample

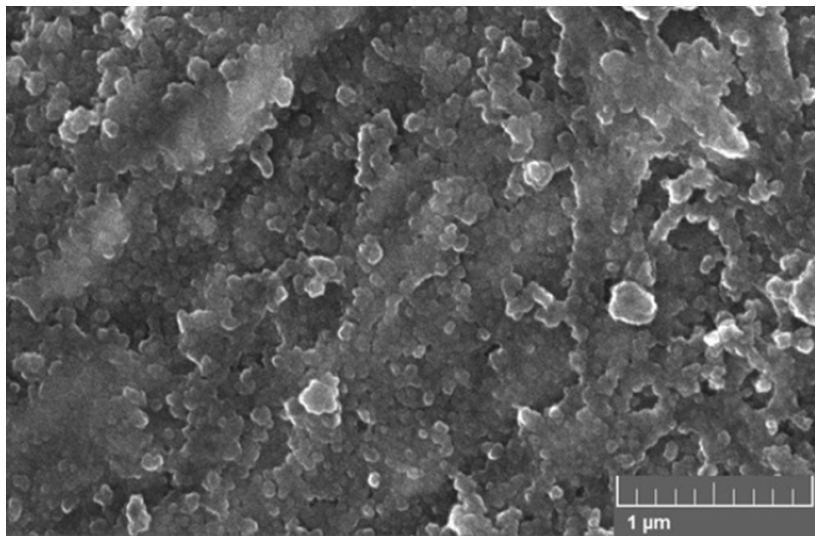

Fig. 8 SEM image of 2H75 sample

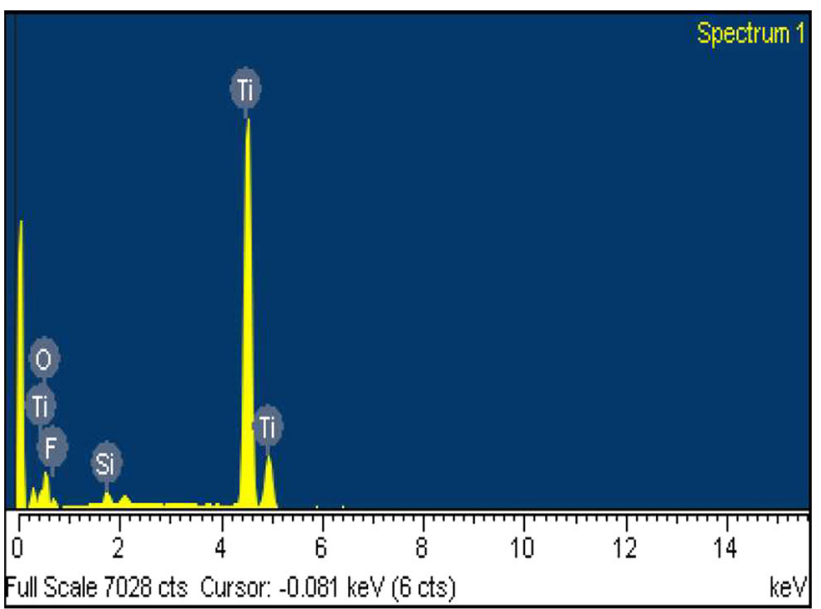

Fig. 9 EDS analysis of 2H75 sample

Table 8 Elemental analysis of 2H75 sample

\begin{tabular}{lcc}
\hline Elements & Weight $\%$ & Atomic\% \\
\hline Iron $(\mathrm{Fe})$ & 5.30 & 9.42 \\
Oxygen $(\mathrm{O})$ & 29.28 & 51.98 \\
Silicon $(\mathrm{Si})$ & 0.96 & 0.96 \\
Titanium $(\mathrm{Ti})$ & 64.46 & 37.64 \\
Total & 100.0 & 100.0 \\
\hline
\end{tabular}




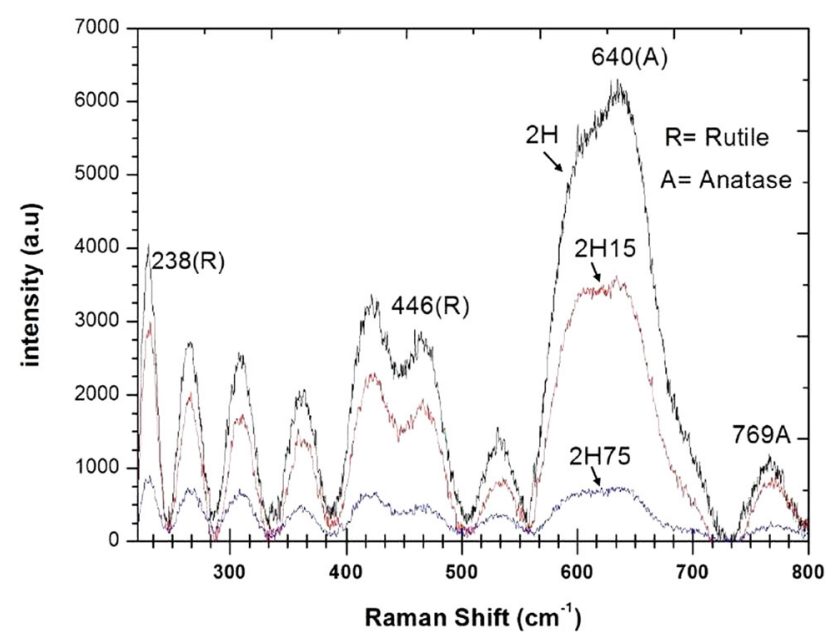

Fig. 10 Raman spectra of anodized samples

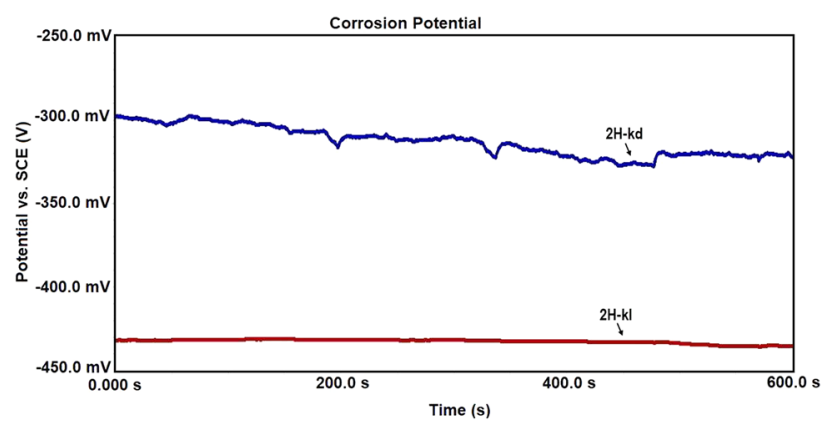

Fig. 11 Corrosion potential of $2 \mathrm{H}$ sample in $\mathrm{KOH}$ solution in dark and in light

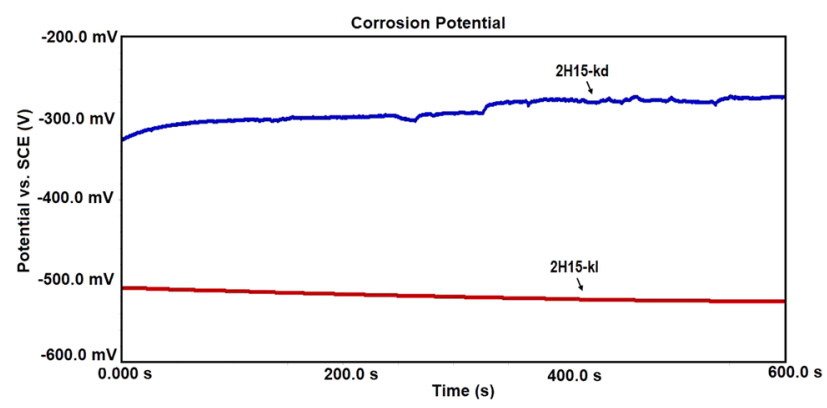

Fig. 12 Corrosion potential of $2 \mathrm{H} 15$ sample in $\mathrm{KOH}$ solution in dark and in light

The specimen $2 \mathrm{H} 75$ showed a decrease in the charge transfer resistance in the presence of light, as shown in Fig. 20. The value of $R_{\mathrm{ct}}$ was initially $8.01 \mathrm{E}-05 \mathrm{~S}^{*} \mathrm{~s}^{\wedge} \mathrm{a}$ in dark which decreases to a value of $1.04 \mathrm{E}-04 \mathrm{~S}^{*} \mathrm{~s}^{\wedge} \mathrm{a}$. This trend shows that the specimen anodized in 2H57 electrolyte has less charge transfer resistance and, hence, more potential to split the water when tested in the presence of light. Figure 21 summarizes EIS trends of all anodized samples in dark and in the presence of light.

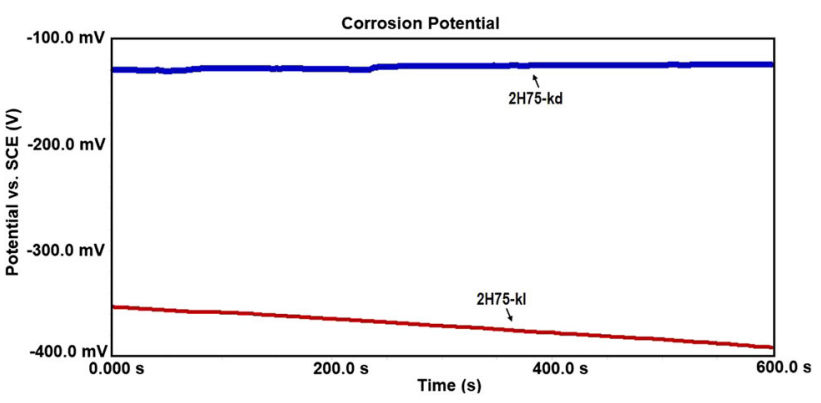

Fig. 13 Corrosion potential of $2 \mathrm{H} 75$ sample in $\mathrm{KOH}$ solution in dark and in light

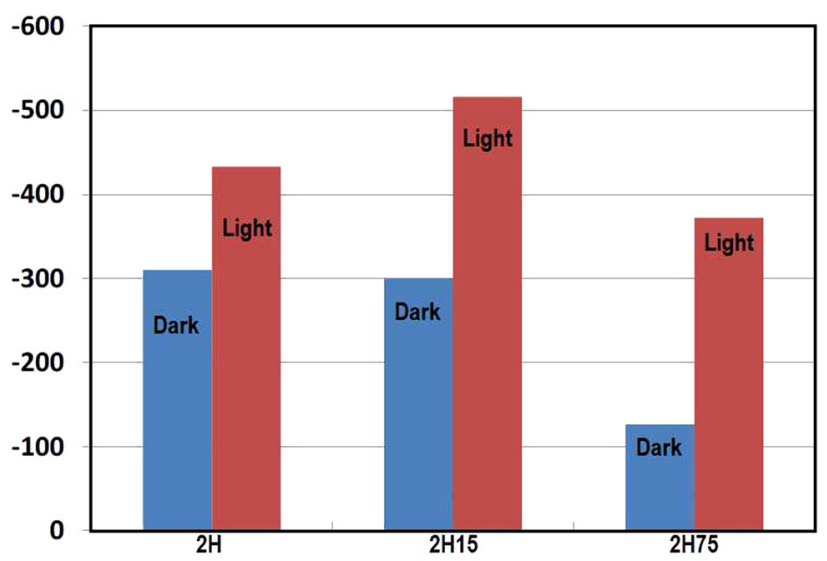

Fig. 14 Trend of $\mathrm{CP}$ of specimens in dark and light

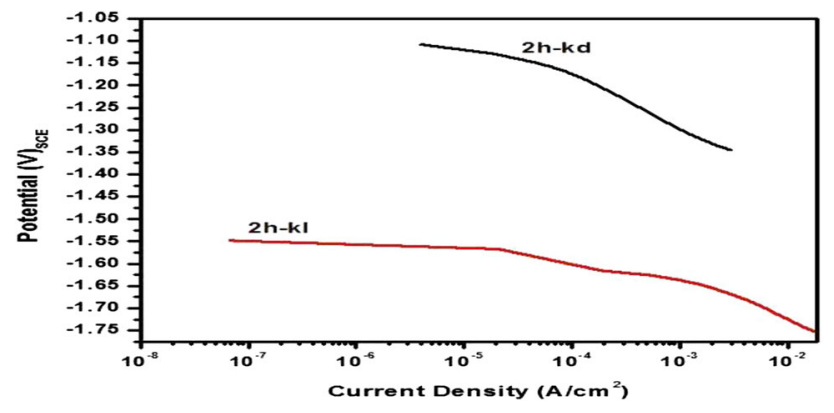

Fig. 15 Potentiodynamic scan of $2 \mathrm{H}$ sample in dark and in light

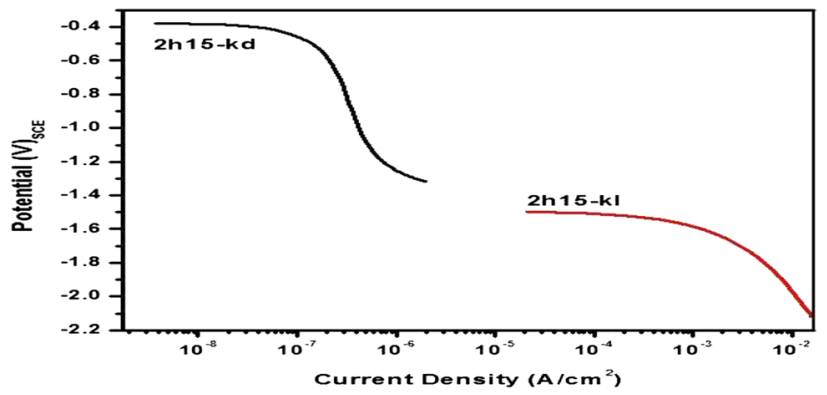

Fig. 16 Potentiodynamic scan of $2 \mathrm{H} 15$ sample in dark and in light 


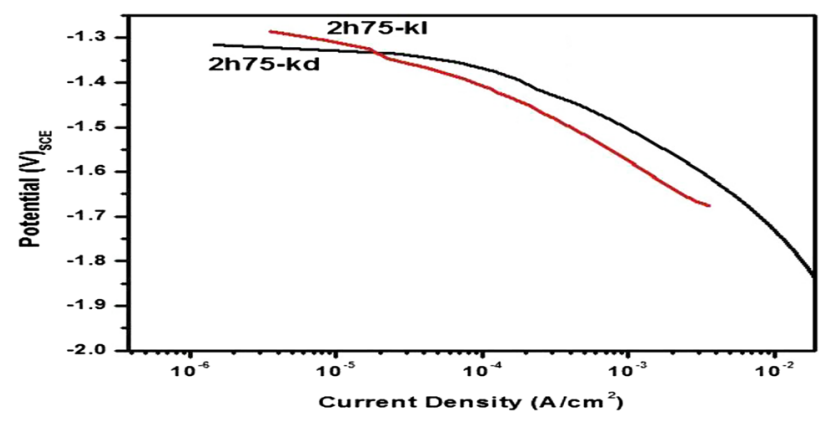

Fig. 17 Potentiodynamic scan of $2 \mathrm{H} 75$ sample in dark and in light

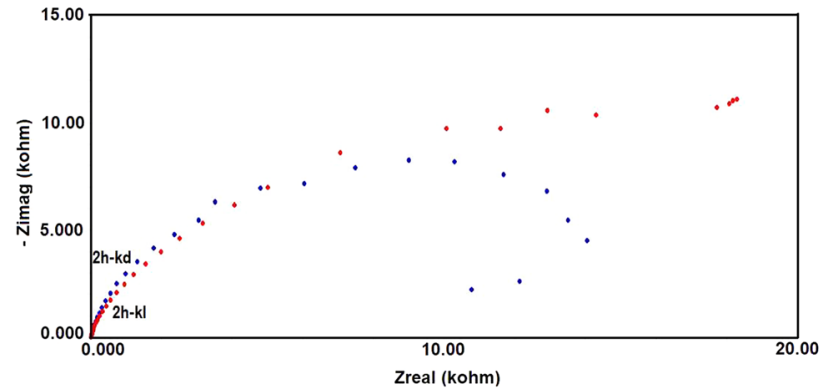

Fig. 18 EIS scan of $2 \mathrm{H}$ sample in dark and in light

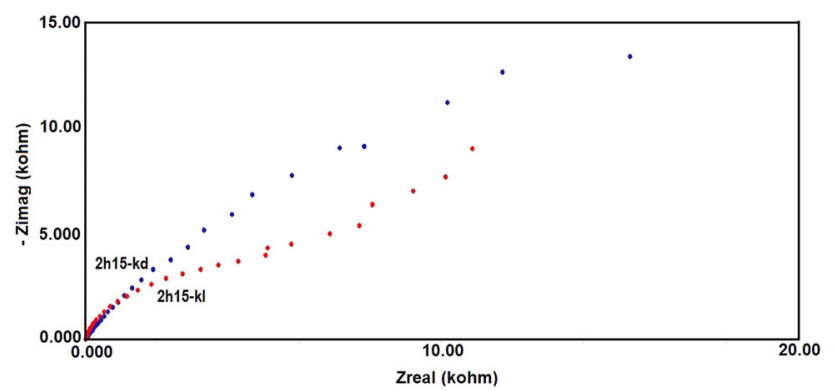

Fig. 19 EIS scan of $2 \mathrm{H} 15$ sample in dark and in light

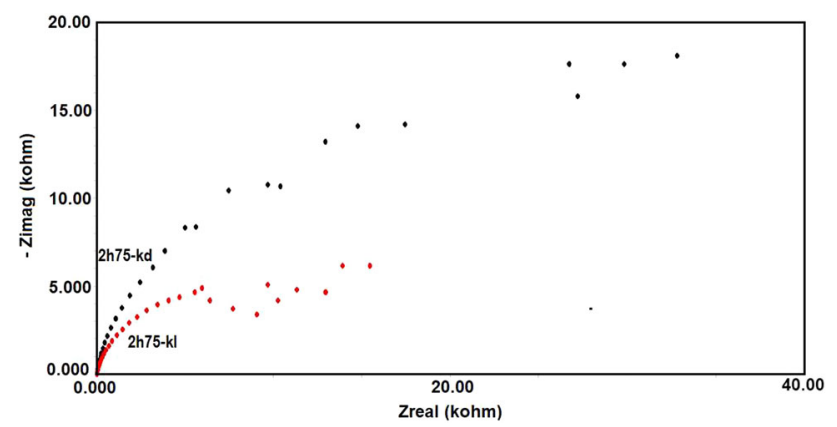

Fig. 20 EIS scan of $2 \mathrm{H} 75$ sample in dark and in light

\section{Conclusions}

The conditions to produce self-organized nanotubular structure on titanium were optimized by anodic potentiodynamic polarization scan. The formation of $\mathrm{TiO}_{2}$ nanotubes in fluoridebased electrolytes was found to be a complex phenomenon. It

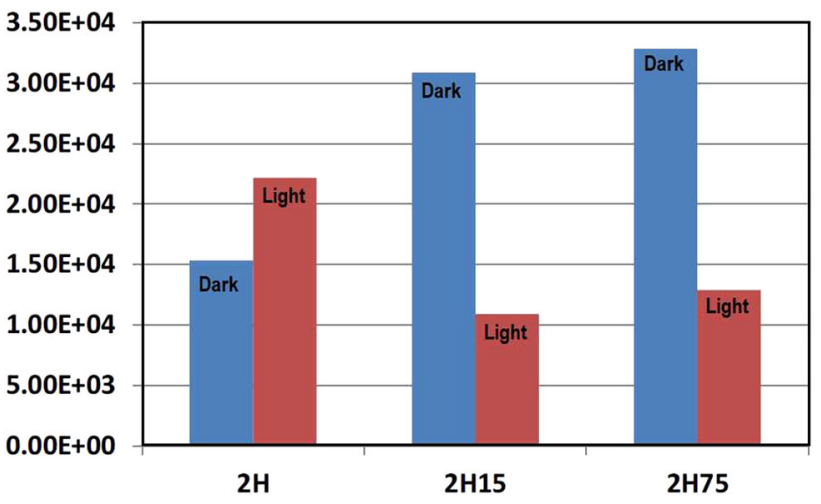

Fig. 21 EIS trends of anodized samples

was found that both the voltage and fluoride ions concentration affect the growth of TNT's equally. The conditions to produce self-organized nanotubular structure on titanium at $30 \mathrm{~V}$ and for 120 min were optimized by potentiodynamic polarization scan. It is found that the concentration of fluoride ions affects the growth of TNTs. The current research work is emphasizing the use of $\left(\mathrm{NH}_{4}\right)_{2} \mathrm{HPO}_{4}$ to modify the extent of self-organization of titania nanotubes. The use of $\left(\mathrm{NH}_{4}\right)_{2} \mathrm{HPO}_{4}$ also reduces the amounts of $\mathrm{NH}_{4} \mathrm{~F}$ to be used in electrolyte and enhanced the capability of hydrogen generation. It is found that the concentration of fluoride ions affects the growth of TNT's. The extent of self-organization was modified with the little addition of $\left(\mathrm{NH}_{4}\right)_{2} \mathrm{HPO}_{4}$ in the electrolyte. Raman spectroscopy confirms the presence of nanotubular structure. The presence of oxygen in the EDS analysis shows the formation of oxide layer. The more negative potential in light shows increase in surface activity which depicts higher hydrogen reduction than in dark. The cathodic polarization trend showed increase in hydrogen reduction reaction in the presence of light. The electrochemical impedance spectroscopy validated the decrease in charge transfer resistance on exposure to light. The electrochemical behavior depicting in hydrogen generation tendency trend was exceptionally lower on sample anodized in $2 \mathrm{H}$ solution compared to $2 \mathrm{H} 15$ and $2 \mathrm{H} 75$ solution which may be related to surface morphology obtained. Comparatively higher efficiency of hydrogen reduction at the surface of $2 \mathrm{H} 15$ was observed as validated by corrosion potential, potentiodynamic, and electrochemical impedance spectroscopy. It is concluded from the results that optimum conditions for the formation of nanotubular structure and its performance towards hydrogen generation were relatively higher for the specimen anodized in 2H15 electrolytes.

Open Access This article is distributed under the terms of the Creative Commons Attribution 4.0 International License (http:// creativecommons.org/licenses/by/4.0/), which permits unrestricted use, distribution, and reproduction in any medium, provided you give appropriate credit to the original author(s) and the source, provide a link to the Creative Commons license, and indicate if changes were made. 


\section{References}

Bauer S, Kleber S, Schmuki P (2006) $\mathrm{TiO}_{2}$ nanotubes: tailoring the geometry in $\mathrm{H}_{3} \mathrm{PO}_{4} / \mathrm{HF}$ electrolytes. Electrochem Commun 8(8):1321-1325. doi:10.1016/j.elecom.2006.05.030

Bozzini B, Carlino P, D’Urzo L, Pepe V, Mele C, Venturo F (2008) An electrochemical impedance investigation of the behaviour of anodically oxidised titanium in human plasma and cognate fluids, relevant to dental applications. J Mater Sci 19(11):3443-3453. doi:10.1007/s10856-008-3487-1

Cochran RE, Shyue JJ, Padture NP (2007) Template-based, nearambient synthesis of crystalline metal-oxide nanotubes, nanowires and coaxial nanotubes. Acta Mater 55:3007-3014. doi:10. 1016/j.actamat.2007.01.005

Diebold U (2003) The surface science of titanium dioxide. Surf Sci Rep 48:53-229

Dobrzański LA, Szindler MM, Szindler M, Lukaszkowicz K, Drygala A, Prokopiuk vel Prokopowicz M (2016) Nanocrystalline $\mathrm{TiO}_{2}$ powder prepared by sol-gel method for dye-sensitized solar cells. Arch Metall Mater 61(2):833-836. doi:10.1515/amm2016-0140

Ellingsen JE (1990) A study on the mechanism of protein adsorption to $\mathrm{Tio}_{2}$. Biomaterials $12: 593-596$

Endut Z, Hamdi M, Basirum WJ (2013) An investigation on formation and electrochemical capacitance of anodized titania nanotubes. Appl Surf Sci 280:962-966. doi:10.1016/j.apsusc. 2013.05.118

Fujishima A, Honda K (1972) Electrochemical photolysis of water at a semiconductor electrode. Nature 238:37-38

Ghicov A, Tsuchiya H, Macak JM, Schmuki P (2005) Titanium oxide nanotubes prepared in phosphate electrolytes. Electrochem Commun 7(March):505-509. doi:10.1016/j.elecom.2005.03.007

Gong D, Grimes CA, Varghese OK, Wenchong H, Singh RS, Chen Z, Dickey EC (2001) Titanium oxide nanotube arrays prepared by anodic oxidation. J Mater Res 16(12):3331-3334

Hoyer P (1996) formation of a titanium dioxide nanotube array. Langmuir 12(6):1411-1413

Kang Misook (2003) Synthesis of $\mathrm{Fe} / \mathrm{TiO}_{2}$ photocatalyst with nanometer size by solvothermal method and the effect of $\mathrm{H}_{2} \mathrm{O}$ addition on structural stability and photodecomposition of methanol. J Mol Catal A 197:173-183

Kasuga T, Hiramatsu M, Hoson A, Sekino T, Niihara K (1999) Titania nanotubes prepared by chemical processing. Adv Mater 11(15):1307-1311

Kim CS, Moon BK, Park JH, Chung ST, Son SM (2003) Synthesis of nanocrystalline $\mathrm{TiO}_{2}$ in toluene by a solvothermal route. J Cryst Growth 254:405-410. doi:10.1016/S0022-0248(03)01185-0

Kitano M, Takeuchi M, Matsuoka M, Thomas JM, Anpo M (2007) Photocatalytic water splitting using Pt-loaded visible lightresponsive $\mathrm{TiO}_{2}$ thin film photocatalysts. Catal Today 120:133-138. doi:10.1016/j.cattod.2006.07.043

Knez M, Nielsch K, Niinistö L (2007) Synthesis and Surface engineering of complex nanostructures by atomic layer deposition. Adv Mater 19(21):3425-3438. doi:10.1002/adma.200700079

Kolen YV, Burukhin AA, Churagulov BR, Oleynikov NN (2003) Synthesis of nanocrystalline $\mathrm{TiO}_{2}$ powders from aqueous $\mathrm{TiOSO}_{4}$ solutions under hydrothermal conditions. Mater Lett 57:1124-1129

Lee J, Jho JY (2011) Fabrication of highly ordered and vertically oriented $\mathrm{TiO}_{2}$ nanotube arrays for ordered heterojunction polymer/inorganic hybrid solar cell. Solar Energy Mater Solar Cells 95(11):3152-3156. doi:10.1016/j.solmat.2011.06.046

Lee K, Mazare A, Schmuki P (2014) One-dimensional titanium dioxide nanomaterials: nanotubes. Chem Rev 114(19):9385-9454
Li JG, Ishigaki T, Sun X (2007) Anatase, brookite, and rutile nanocrystals via redox reactions under mild hydrothermal conditions: phase-selective synthesis and physicochemical properties. J Phys Chem C 111(13):4969-4976

Lim CL, Zainal Z, Hussein MZ, Tan W (2012) Effect of electrolyte composition in electrochemical synthesis of self-. Adv Mater Res 364:298-302. doi:10.4028/www.scientific.net/AMR.364. 298

Macak JM, Tsuchiya H, Ghicov A, Yasuda K, Hahn R, Bauer S, Schmuki P (2007) $\mathrm{TiO}_{2}$ nanotubes: self-organized electrochemical formation, properties and applications. Curr Opin Solid State Mater Sci 11(1-2):3-18. doi:10.1016/j.cossms.2007.08.004

Marcus P (2002) Corrosion mechanisms in theory and practice, 2nd edn. CRC Press, Boca Raton

Marichy C, Bechelany M, Pinna N (2012) Atomic layer deposition of nanostructured materials for energy and environmental applications. Adv Mater 24(18):1017-1032. doi:10.1002/adma. 201104129

Meekins BH (2012) Controlling interfacial transfer processes for improved photoelectrochemical performance. University of Notre Dame, Notre Dame

Mishra PR, Shukla PK, Singh AK, Srivastava ON (2003) Investigation and optimization of nanostructured $\mathrm{TiO}_{2}$ photoelectrode in regard to hydrogen production through photoelectrochemical process. Int J Hydrog Energy 28:1089-1094

Mo SD, Ching WY (1995) Electronic and optical properties of three phases of titanium dioxide: rutile, anatase, and brookite. Phys Rev B 51(19):23-32

Momeni MM, Ghayeb Y (2016) Fabrication, characterization and photoelectrochemical performance of chromium-sensitized titania nanotubes as efficient photoanodes for solar water splitting. J Solid State Electrochem 20(3):683-689. doi:10.1007/s10008015-3093-3

Nada AA, Barakat MH, Hamed HA, Mohamed NR, Veziroglu TN (2005) Studies on the photocatalytic hydrogen production using suspended modified $\mathrm{TiO}_{2}$ photocatalysts. Int $\mathrm{J}$ HydrogEnergy 30:687-691. doi:10.1016/j.ijhydene.2004.06.007

Nian JN, Teng H (2006) Hydrothermal synthesis of single-crystalline anatase $\mathrm{TiO}_{2}$ nanorods with nanotubes as the precursor. J Phys Chem B 110(9):4193-4198

Paulose M, Mor GK, Varghese OK, Shankar K, Grimes CA (2006) Visible light photoelectrochemical and water-photoelectrolysis properties of titania nanotube arrays. J Photochem Photobiol, A 178:8-15. doi:10.1016/j.jphotochem.2005.06.013

Ratner DB, Brunette DM, Tengvall P, Textor M, Thomsen P (2008) Titanium in medicine. J Eng Med. doi:10.1243/ 0954411021536432

Salari M, Aboutalebi SH, Konstantinov K, Liu HK (2011) A highly ordered titania nanotube array as a supercapacitor electrode. Phys Chem Chem Phys 13:5038-5041. doi:10.1039/c0cp02054k

Shin H, Jeong DK, Lee J, Sung MM, Kim J (2004) Formation of $\mathrm{TiO}_{2}$ and $\mathrm{ZrO}_{2}$ nanotubes using atomic layer deposition with ultraprecise control of the wall thickness. Adv Mater 16(14):1197-1200. doi:10.1002/adma.200306296

Sreekantan S, Hazan R, Lockman Z (2009) Photoactivity of anataserutile $\mathrm{TiO}_{2}$ nanotubes formed by anodization method. Thin Solid Films 518(1):16-21. doi:10.1016/j.tsf.2009.06.002

Sul YT, Johansson CB, Jeong Y, Albrektsson T (2001) The electrochemical oxide growth behaviour on titanium in acid and alkaline electrolytes. Med Eng Phys 23:329-346

Tan AW, Pingguan-Murphy B, Ahmad R, Akbar SA (2012) Review of titania nanotubes: fabrication and cellular response. Ceram Int 38(6):4421-4435. doi:10.1016/j.ceramint.2012.03.002

Tang H, Prasad K, Sanjinès R, Schmid PE, Lévy F (1994) Ellectrical and optical properties of $\mathrm{TiO}_{2}$ anatase thin films. J Appl Phys 75(4):2042-2047. doi:10.1063/1.356306 
Taveira LV, Macak JM, Sirotna K, Dick LFP, Schmuki P, Electrochem Soc J, B-b Pages et al (2006) Voltage oscillations and morphology during the galvanostatic formation of selforganized $\mathrm{TiO}_{2}$ nanotubes. J Electrochem Soc 153(4):B137B143. doi:10.1149/1.2172566

Tsai CC, Nian JN, Teng H (2006) Mesoporous nanotube aggregates obtained from hydrothermally treating $\mathrm{TiO}_{2}$ with $\mathrm{NaOH}$. Appl Surf Sci 253(4):1898-1902. doi:10.1016/j. apsusc.2006.03.035

Yao C, Webster TJ (2006) Anodization: a promising nano-modification technique of titanium implants for orthopedic applications. J Nanosci Nanotechnol 6(9):2682-2692. doi:10.1166/jnn.2006. 447

Yi H, Peng T, Ke D, Ke D, Zan L, Yan C (2008) Photocatalytic $\mathrm{H}_{2}$ production from methanol aqueous solution over titania nanoparticles with mesostructures. Int J Hydrog Energy 33:672-678. doi:10.1016/j.ijhydene.2007.10.034

Yin S, Fujishiro Y, Jihuai W, Aki M, Sato T (2003) Synthesis and photocatalytic properties of fibrous titania by solvothermal reactions. J Mater Process Technol 137:45-48
Zazpe R, Knaut M, Sopha H, Hromadko L, Prikryl J, Gartnerova V, Bartha JW, Macak Jan M (2016) Atomic layer deposition for coating of high aspect ratio $\mathrm{TiO}_{2}$ nanotube layers. Langmuir 32(41):10551-10558. doi:10.1021/acs.langmuir.6b03119

Zhang D, Yoshida T, Minoura H (2003) Low-temperature fabrication of efficient porous titania photoelectrodes by hydrothermal crystallization at the solid/gas interface. Adv Mater 15(10):814-817. doi:10.1002/adma.200304561

Zwilling V, David D, Perrin MY, Aucouturier M (1999) Structure and physicochemistry of anodic oxide films on titanium and TA6V alloy. Surf Interface Anal 27(7):629-637

\section{Publisher's Note}

Springer Nature remains neutral with regard to jurisdictional claims in published maps and institutional affiliations. 